\title{
EDUCAÇÃO PELA PESQUISA COMO MODO, TEM PO \\ E ESPAÇO DE QUALIFICAÇÃO DA FORMAÇÃO DE PROFESSORES DE CIÊNCIAS
}

\author{
M aria do Carmo Galiazzi ${ }^{1}$ \\ Roque M oraes ${ }^{2}$
}

\begin{abstract}
Resumo: 0 presente artigo propõese a reunir argumentos em favor do educar pela pesquisa como modo, tempo e espaço de formação docente. Iniciando-se por apresentar alguns princípios que fundamentam o educar pela pesquisa, mostra-se sempre com exemplificações práticas, como esses podem ser implementados pelo uso de um ciclo de pesquisa constituído por questionamento, argumentação e validação. Procura se mostrar também como esse encaminhamento da formação de professores possi bilita uma educação com qualidade formal e política. Conclui-se o texto com alguns argumentos que sustentam que o educar pela pesquisa possi bilita superar algumas limitações históricas dos cursos de formação de professores.
\end{abstract}

Unitermos: educar pela pesquisa, formação de professores de Ciências

Abstract: This paper presents some arguments intending to demonstrate the strenghts of educating through inquiry as a way, a time and a space for teacher education. Starting with the presentation of some principles that base education through inquiry, it is showed, always based on practical examples, how these may be implemented with the use of an inquiry cycle formed by questioning, argumenting and validating. It is also intended to show how this process of teacher education may reach a high for-mal and political quality. In condusion it is argued that educating through inquiry may help to over-come some historical limitations of teacher education courses.

Keywords. educating through inquiry, Science teacher education

\section{Introdução}

0 presente trabal ho argumenta em favor do educar pela pesquisa como modo, espaço e tempo de qual ificação dos cursos de formação de professores. 0 el emento central de argumentação é a idéia de que a qualidade da formação inicial de professores pode ser melhorada com a integração da pesquisa no processo desta formação.

0 texto explora inicialmente alguns dos fundamentos desse entendimento sobre a formação do professor; em continuidade apresenta-se esta abordagem como um ciclo baseado em três momentos principais: questionamento, argumentação e validação; a partir disto pretende-se mostrar como o educar pela pesquisa possibilita uma qualificação formal e política da formação inicial de professores.

O s argumentos apresentados são resultados de diálogos com os teóricos que estudam a formação de professores e de diálogos com a realidade pesquisada que foi de professores que, em cursos de Licenciatura em Ciências ( $Q$ uímica, Física, Ciências), fazem da pesquisa pressuposto pedagógico. Foram analisados cinco tipos de experiências de pesquisa em sala de aula, com 14 professores envolvidos, alguns deles trabalhando em grupos com os alunos, constituindo-se dessa forma em coletivos de pesquisa. Os dados foram coletados a partir de entrevistas com estes professores e triangulados por avaliações escritas, relatos da sala de aula

\footnotetext{
1 Professora Adjunta no D epartamento de Q uímica e no M estrado em Educação Ambiental da Fundação U niversidade do Rio Grande. Rio Grande, Rio Grande do Sul, Brasil. (email: carmo@mikrus.com.br)

2 Professor Assistente D outor do Programa de Pós-graduação de Educação e do M estrado em Ensino de Ciências da Pontifícia Universidade Católica do Rio Grande do Sul. Porto Alegre, Rio Grande do Sul, Brasil. (email: searom@pucrs.br)
} 
e entrevistas com 45 alunos destes professores, em disciplinas de caráter pedagógico e de conteúdos específicos.

Em síntese, o objetivo do texto é reunir argumentos teóricos e práticos que apóiem a tese de que a formação inicial de professores pode ser aperfeiçoada pelo uso da pesquisa no espaço escolar.

\section{Princípios da educação pela pesquisa}

A iniciativa de repensar e reestruturar a formação de professores com base no educar pela pesquisa, para poder atingir a melhoria de sua qualidade, parte da convicção da necessidade de superar a aula caracterizada pela simples cópia, a nova formação se constituirá em uso da pesquisa como atitude cotidiana na sala de aula.

Isso implica em transformar os licenciandos, de objetos, em sujeitos das relações pedagógicas, assumindo-se autores de sua formação por meio da construção de competências de crítica e de argumentação, o que leva a um processo de aprender a aprender com autonomia e criatividade.

$\mathrm{N}$ isso assume um papel essencial o exercício do escrever em que, por meio de interlocuções com teóricos e com a realidade, os alunos-autores expressam suas aprendizagens, sempre as submetendo a críticas rigorosas e qual ificadas.

$N$ esse mesmo processo já se subentende uma nova visão do processo avaliativo, conduzido essencialmente com base nas produções dos participantes.

São estes os princípios que abordaremos e defenderemos nesta parte do texto: autonomia para aprender a aprender; 0 exercício da escrita para pensar e avaliação pela produção dos alunos.

A educação pela pesquisa tem como motusinicial a superação da aula copiada. Surge assim a pesquisa como princípio educativo (D emo, 1997a) e como modelo didático do professor (Porlán, 1998; Porlán e Rivero, 1998).

Propõe-se fazer da pesquisa expediente pedagógico, transformando-se as aulas em espaço, modo e tempo de pesquisa, entendida num sentido que vai além das caracterizações em que costuma ser assumida. A essência deste entendimento de pesquisa é 0 questionamento, a argumentação e a crítica e validação dos argumentos assim construídos.

Assumir o educar pela pesquisa implica em assumir a investigação como expediente cotidiano na atividade docente. 0 pesquisar passa a ser princípio metodológico diário de aula. 0 trabalho de aula gira permanentemente em torno do questionamento reconstrutivo de conhecimentos já existentes, que vai além do conhecimento de senso comum, mas o engloba e enriquece com outros tipos de conhecimento dos alunos e da construção de novos argumentos que serão validados em comunidades de discussão crítica.

I sso não é necessariamente compreendido com facilidade por professores e alunos. O s alunos apresentam um grau de dificuldade no início, tendo em vista entendimentos anteriores sobre 0 ensinar e 0 aprender difíceis de serem alterados (Galiazzi, 2000). 0 desafio do professor é conseguir transformar essas visões, convertendo os conteúdos a serem trabalhados em pesquisa, conforme descreve uma das professoras entrevistadas:

"U m dos trabal hos que foi desenvolvido, em função da questão da linguagem, surgiu quando, em aula prática, um aluno falou que o ácido sulfúrico quei mava o papel. A partir daí, propus uma discussão sobre combustão e de um questionário por todos respondido, cada um de nós fez uma síntese de uma questão, e eles começaram a ver que nem todos pensam igual. Em aula foi feita uma análise dos resultados, mostrando as diferentes concepções, tendo por referência um texto teórico." 
0 relato descreve 0 início de uma pesquisa a partir do questionamento sobre um dos conteúdos da disciplina que é combustão. 0 questionário tinha por objetivo explicitar 0 conhecimento dos alunos sobre o tema em estudo. 0 processo de pesquisa desenvolveu-se a partir da análise dos dados coletados feita pel os alunos com auxílio da professora e com interpretação realizada por leitura de referencial teórico pertinente. Conteúdos específicos ou pedagógicos podem ser trabalhados em forma de pesquisa, como exemplifica um dos professores entrevistados: ... eles fazem inicialmente uma reflexão sobre a própria experiência como alunos, identificando modelos de ensino ejá apontando um modelo desejável. Após inicia-se um processo de questionamento sobre alguns obstáculos profissionais (epistemológicos: veracidade do conhecimento científico; psicológicos: aprendizagem simplista, receptiva; etc.). Tudo isso se faz com coleta de dados, observação de aulas, entrevistas com professores, análises de textos sobre pesquisa didática, discussões em grupo, reflexões individuais, registro com rigor da evolução das próprias idéias, etc.

$N$ esse processo, todos os envolvidos passam a ser sujeitos das atividades. São autores da reconstrução de seus próprios conhecimentos. 0 s trabal hos se relacionam intimamente com o que os participantes pensam e fazem. Professor e licenciandos, numa formação por meio da pesquisa, constituem-se em pesquisadores de suas teorias e práticas pedagógicas, originando-se uma interação cooperativo-participativa capaz de ajudar a evoluir positivamente. Por isto o grupo organiza-se coletivamente, focalizando-se um ou mais projetos de pesquisa, como mostra o relato:

"Eu sempre discuto com os alunos em uma ou duas aulas como é que o projeto vai ser feito. Àsvezes eu tenho uma idéa, mas eu trago para que elesassumam todos juntos essa idéia. Se eu trouxer um projeto pronto, eles não vão ser co-responsáveis pelo projeto."

D izemos que nesse processo as relações pedagógicas são transformadas, desaparecendo os alunos-objetos e emergindo os participantes-sujeitos. É importante salientar também que os questionamentos se dão sobre os conhecimentos dos alunos, no sentido de sua reconstrução. Todo este processo envolve o aluno de modo intenso e faz com que ele mesmo se perceba aprendendo, conforme relatam dois alunos:

"Considero o processo (ler, escrever e divulgar oralmente) fascinante, pois consigo me ver como um sujeito construtor de conhecimento. U m conhecimento queéfundamental para a minha ação docente.

Estamos sempre tendo que ler, escrever ou falar e isso ajuda muito na minha formação acadêmi ca. Às vezes, começo a ler trabalhos realizados nos anos anteriores e vejo o quanto melhorei e espero melhorar cada vez mais."

0 princípio do diálogo e discussão críticos está sempre presente em um ambiente de educação pela pesquisa. Pensa-se por meio do diálogo; exercita-se a discussão constantemente. $0 \mathrm{~s}$ participantes assumem suas idéias e argumentos, ainda que submetendo-os à crítica constante. Q ualquer argumento dos sujeitos envolvidos no processo é inicialmente tomado como válido, mas é no diálogo entre os participantes, fundamentado em teóricos e na realidade empírica que al guns destes argumentos se estabelecem com mais força. É de destacar ainda que todo o processo é conduzido numa grande riqueza metodológica, conforme relata uma aluna envolvida neste tipo de trabalho:

"O normal era no início da aula termos um grande grupo, que seria o grupo de pesquisa em que, então, tinha os mestrandos, os alunos de iniciação científica, os professores e 
os alunos da disciplina. N ós fazíamos sempre um grande círculo e o trabalho era encaminhado coletivamente. A estrutura do trabal ho variava. Podia ocorrer no grandegrupo ou em gruposmenores, eisso nós combinávamos sempreem função da forma em que o trabalho estava se encaminhando."

No conjunto das descrições evidencia-se que educar pela pesquisa leva a aprender a aprender (D emo, 1997b). É exercício de aprender autônomo e participativo. É meio de aprender em que todos se envolvem na aprendizagem de cada um dos participantes. Isto se dá pelo desenvolvimento da capacidade de elaboração própria, sinalizada pela habilidade em desenvolver argumentos fundamentados oral mente e pela qualidade das elaborações textuais dos envolvidos.

Este aprender a aprender não só é conseqüência da construção de outro modelo de ação em sala de aula, como também possibilita aos alunos compreenderem a incompletude de toda a aprendizagem, segundo os depoimentos de um professor e de uma aluna:

"Aprender a aprender está o tempo todo presente porque é a idéia da superação da aula copiada; quer dizer, ainda que se falasse, que se dialogasse, que se tentasse expor coisas, não era um programa fixo e que tinha que ser cumprido.

N este tipo de disciplina, se aprende a continuar buscando sobre um mesmo assunto. 0 conteúdo não vai estar pronto, acabado. 0 aluno sempre vai aprender alguma coisa a mais, e isso vai ser um processo permanente, para sempre."

No educar pela pesquisa, conduzindo ao aprender a aprender, faz-se do escrever maneira de pensar, isto é, pelo exercício da escrita aprende-se a pensar por mão própria e nisto está um entendimento inovador. A lógica tradicional inverte-se. Do pensar para escrever desenvolve-se o escrever para pensar. A produção textual é modo de organizar a aprendizagem, a reflexão e o próprio pensamento, como afirma um aluno após passar por uma experiência curricular em que o texto era melhorado em processos de reescrita:

"Acredito que, apesar dos problemas que posso apresentar em escrever, penso que todos nós devemos aprender a regular nossos pensamentos através da escrita. I sto é, devemos perceber esta forma de comunicação como um meio pelo qual aprendemos."

Pensa-se e produz-se, inicialmente, por meio da escrita individual, sustentada por meio de interlocuções teóricas e empíricas; a seguir esta produção é submetida à crítica de um grupo para sustentação e validação.

U m dos modos de argumentar com qualidade e rigor é a sustentação de argumentos por intermédio de interlocutores teóricos. 0 diálogo com teóricos, validando e fundamentando os argumentos dos sujeitos participantes, dá significado cada vez mais aprofundado às próprias teorias que estão sendo reconstruídas. D este modo a busca de interlocutores teóricos constitui-se em ampliação do grupo de participantes no diálogo de uma aula com pesquisa.

U ma das professoras entrevistadas destaca como estas reconstruções precisam acontecer a partir do conhecimento e prática inicial dos participantes.

"O s alunos aprendem a ser questionadores. Eles não aceitam verdades impostas, verdades prontas. Eles questi onam constantemente seus fazeres, seus referenciais teóri cos, suas crenças sobre o trabalho. A cho que isso faz com que a gente fi que questionando permanentemente todo o trabalho que a gente faz. I sso faz com que a gente procure sempre por novas alternativas." 
As produções escritas validam-se também pelas interlocuções com a realidade prática investigada. Fundamentar e exemplificar os argumentos construídos em dados empíricos ou exemplos práticos constitui importante forma de sua validação. É o que Bernardo Gustavo (2000) denomina ancoragem dos argumentos na realidade prática, sendo esta realidade, espe cialmente, o contexto dos participantes, seus próprios conhecimentos e práticas. Um professor enfatiza esse ponto com um exemplo de pesquisa sobre o conhecimento químico:

"Então a gente fez esta divisão entre alunos de Q uímica, de cursos afins e de cursos sem relação com a Q uímica, para ver o tipo de argumento que os alunos colocavam ou o tipo de enunciado, e para ver se tinha uma relação. A nossa hi pótese era de que o aluno do curso de Q uímica forneceria uma definição mais química, mais de livro, mais teórica. E 0 aluno que nada tinha a ver com o curso apresentaria uma definição mais de vida, de vivência."

0 mesmo professor ainda reflete sobre a necessidade, no educar pela pesquisa, de estabelecer pontes com a realidade:

“... aprende a ol har esta realidade através da análise crítica,... ajuda a enxergar melhor a realidade. Formar professores críticos contribui para se ter a formação de um aluno melhor lá na escola de ensino fundamental ou médio."

Finalmente, em função de tudo que foi exposto, a educação pela pesquisa requer modos de avaliação que superem as atitudes sansionadoras da avaliação em seu sentido tradicional. A avaliação numa perspectiva de mediação acompanha todas as etapas da produção num processo de educação pela pesquisa. D ando-se por meio do diálogo e crítica constantes, a avaliação passa a ser função não só do professor, mas de todos os participantes. Avalia-se para ajudar o outro a aperfeiçoar seus questionamentos, produções e argumentações. U ma professora, atestando especialmente que se trata de um processo que contempla tanto professor como alunos, assim se posiciona em relação ao tema:

"Eu faço uma avaliação que enfatiza a avaliação do aluno. Eu avalio o aluno, ele se avalia, eu me avalio e ele me avalia. I sso acontece em todo bimestre; são momentos que perpassam a disciplina. Eu solicito que ele avalie o processo, que ele sugira."

Assim conduzida, a própria avaliação se transforma em pesquisa, capaz de reorientar o processo no sentido de aprendizagens mais qualificadas.

Com isto completamos o primeiro conjunto de argumentos a favor de nossa tese da formação docente com base no educar pela pesquisa. Pressupõe um conjunto de princípios: questionamento reconstrutivo; argumentação competente efundamentada; crítica e discussão permanentes a partir de produções escritas dos participantes, tipo de envolvimento em que os participantes se assumem sujeitos de suas produções, superando-se dessa forma a aula copiada e atingindo-se 0 aprender com autonomia e significado.

A partir disto propomos discussões no sentido de modos de encaminhamento destas iniciativas em sala de aula. Isto pode ser consubstanciado em forma do que denominamos 0 ciclo do educar pela pesquisa. Por meio dele pode-se concretizar os modos, tempos e espaços de uma formação qualificada de professores pela pesquisa, tema a ser abordado em seqüência.

\section{Práticas do educar pela pesquisa}

Partindo-se do pressuposto de que todo conhecimento e toda prática são essencialmente incompletos e passíveis de superação, a educação pela pesquisa pode ser compreendida 
como um ciclo dialético e recursivo que se inicia com um questionamento, seguido de tentativas de reconstruir conhecimentos e práticas pela organização e defesa de novos argumentos. Estes, comunicados e submetidos a uma comunidade crítica, serão avaliados e aperfeiçoados gradativamente.

0 educar pela pesquisa, descrito por meio do ciclo de questionamento, argumentação e validação crítica, pode ser organizado segundo diferentes modos estruturais. Pode darse, por exemplo, pelo envolvimento de toda uma classe de alunos num único projeto: "Esta pesquisa aconteceu há três semestres e os alunos tinham que entrevistar seus colegas ou outros universitários sobre qual concepção que eles tinham a respeito de ácido..."

Pode também ser organizado pelo encaminhamento simultâneo de várias pesquisas menores em grupos, conforme relato de uma das professoras: "São fei tos vários trabalhos. Temos dez assuntos. Cada um tem o seu. U m deles, por exemplo, foi a identificação da composição química da beterraba. Eles começaram identificando os pigmentos da beterraba..."

0 trabalho não implica, necessariamente, em projetos de investigação no sentido tradicional, mas pode consistir, segundo sugestão de D emo (1997a), em dividir um tema entre os participantes, cabendo a cada um deles pesquisar e colocar à crítica do grupo sua produção num tema específico. Esta forma de organização aparece, por exemplo, na proposta didática de um dos professores investigados: ... o tema de pesquisa é avaliação. As pessoas começam por trazer os mais diversos assuntos e acaba sendo uma ampla gama de temas sobre avaliação. D epois se começa a organizar, mostrar como é que se pode fazer. Claro que tem a idéia de categorizar, de organizar isso em grupos de idéias semelhantes. Começa-se a olhar vários aspectos. Claro que nesse momento já se leva para o grupo al gumas idéias, autores, uma fundamentação que já se tenha trabalhado para ajudar a esquematizar isso.

Em todas estas formas de organização o professor assume o papel central de mediador do processo, ainda que também ele possa assumir pesquisas que concretiza juntamente com seus alunos. C ada um destes formatos terá finalidades e possibilidades específicas, podendo ser selecionadas em função das vivências e experiências anteriores tanto de professores como de alunos.

0 educar pela pesquisa, enquanto pressupõe, também alimenta a capacidade de entender-se incompleto, de que todo conhecimento e prática podem sempre ser aperfeiçoados. As oportunidades de aprendizagem são novos momentos para reiniciar e completar a própria formação. A partir disto o aprendiz se integra em um movimento dialético em que continuamente pode superar-se e superar seus conhecimentos e suas práticas. Também nisto está incluída a idéia de que os avanços não são lineares. Sempre há tropeços. A evolução se dá por avanços e recuos. É necessário conviver com a dúvida e a incompletude. Esta é também, em essência, a concepção de ciência subentendida no educar pela pesquisa, uma busca de um conhecimento sempre inacabado.

A pesquisa em sala de aula tem no questionamento seu elemento desencadeador. Demo (1997b) denomina de questionamento reconstrutivo este exercício constante de perguntar, de alimentar dúvidas, de perceber lacunas de conhecimento, sejam conhecimentos específicos de uma disciplina, sejam conhecimentos didáticos e metodológicos. Entretanto, mesmo que possam envolver elementos externos, o questionamento sempre se inicia nos conhecimentos e práticas próprios dos sujeitos envolvidos, como descreve uma das professoras:

"Eu busco sempre trazer o pensamento do aluno sobre o que está sendo di scutido em aula. Isso no conhecimento químico tem mostrado ser muito rico, porque ao propor al guma atividade em que 0 aluno tenha que prever resultados, representar modelos, 
justificar experimentos, ficam explicitados os conhecimentos iniciais dos alunos. N estes dias, em uma aula sobre evaporação, um dos modelos explicativos foi que as moléculas, ao mudarem de estado físico, mudavam de tamanho."

A explicitação do conhecimento dos alunos mostra claramente alguns aspectos do conhecimento químico que precisam ser discutidos com os al unos para que eles se apropriem ou ampliem seu conhecimento químico. Essa característica é que garante a qualidade de uma pesquisa: questionar e poder ser questionado. É por meio do reconhecimento de lacunas teóricas e práticas que podemos aprender e avançar em nossos conhecimentos como mostra 0 relato da mesma professora em outra disciplina:

"N o grupo de pesquisa com professores da rede municipal de ensino, propus um exercício como forma de explicitação do conhecimento inicial. M ostrei um copo com água e gelo e pedi para eles desenharem um modelo explicativo para o que estavam vendo. U m dos professores do grupo questionou o exercício apresentando uma teoria muito mais complexa de ligações intermoleculares do que a que eu apresentei. I sso para mim deixou evidente a riqueza desta sistemática, estar aberto a aprender com o outro."

0 questionamento reconstrutivo pode ser considerado como o primeiro momento da educação pela pesquisa. Q uem questiona um conhecimento ou uma prática existente precisa trazer uma proposta nova que substitua aqueles el ementos questionados. Precisa construir novos argumentos. Precisa reconstruir o questionado. É o que denominamos de construção de novos argumentos. D este modo a construção de argumentos é uma forma de assumir-se como sujeito dentro do discurso, como fica expresso no discurso de uma aluna:

"Saí do ensino médio com o entendimento da teoria de Arrhenius sobre ácidos, talvez porque seja a mais simples e a mais usada em Química Analítica. Na verdade, me foram apresentadas também a teoria de Brönsted-Löwry e a teoria de Lewis, mas o que uma adolescente faz com etas teorias se nem nos jornais elas aparecem? Agora adulta e trabalhando com substâncias orgânicas, entendo a importância de aprender outras teorias, como as citadas anteriormente."

O s argumentos propostos precisam ser rigorosos e fundamentados. U ma educação pela pesquisa necessita desenvolver nos participantes a capacidade de construir argumentos críticos e coerentes, capazes de serem defendidos em comunidades de crítica, seja em nível de sala de aula, seja em grupos além dela. A competência argumentativa é uma das metas de toda educação pela pesquisa.

Essa construção de argumentos dá-se a partir de operações num mundo que se constitui pela linguagem. Requer a utilização de recursos culturais como 0 diálogo, a escrita e a leitura para sua concretização. Entretanto, o educar pela pesquisa não apenas se utiliza da linguagem em seu processo de produção de novos conhecimentos, mas também pretende desenvolver as potencialidades dos participantes no uso dessa linguagem, constituindo-se dessa forma de maneira mais competente como sujeitos, como atesta uma aluna ao falar sobre as aprendizagens em uma disciplina de Q uímica:

"A aprendizagem mais importante, o início de tudo, foi o estudo do petróleo. Fiquei muito interessada, me fez procurar em livros, pesquisar na internet, obter informações junto à Refinaria de Petróleo I piranga. Aprendi conteúdos que considero básicos para um aluno de Q uímica como: formação e extração de petróleo, principais países produtores, processo de refino, destilação, xisto betuminoso. D epois de feito este estudo, 
resolvi abrir na página do primeiro dia e ler o que eu havia escrito sobre petróleo. Fiquei perplexa com a minha falta de conhecimento sobre um assunto tão importante para um estudante de Q uímica."

Argumentos de qualidade não nascem acabados e rigorosos. Precisam ser submetidos a um aperfeiçoamento gradativo. Isto acontece, numa primeira instância, por avaliação entre pares. Um processo cíclico e recursivo de escrita, crítica e reconstrução que permite 0 aperfeiçoamento das produções. Nisso atingem-se metas não só de produções de qualidade, mas igualmente desenvolvem-se nos participantes capacidades críticas cada vez mais agudas.

Esse é um processo lento. Um exercício de escrita com alunos em uma disciplina de Q uímica mostrou resultados significativos, como pode ser percebido pelo que uma aluna inicialmente representou ao escrever porque as substâncias químicas reagiam:

As substâncias reagem

- dissociarem $(\mathrm{NaCl}+\mathrm{H} 20) \longrightarrow \mathrm{Na}+(\mathrm{aq})+\mathrm{Cl}-(\mathrm{aq})$

- estabilidade

N um exercício de reescrita posterior pode ser percebido o efforço da aluna em escrever e neste exercício de escrita fica expressa a falta de clareza quanto a este conhecimento químico.

"Assubstâncias reagem em busca de uma melhor estabilidade. Parecesimples, mas me faço a seguinte pergunta: Se este éo motivo, então por que as substâncias estáveis reagem? Penso que pode ser porque em presença de outras substâncias estas se desestabilizam e deste modo novamente tendem a buscar sua forma mais estável. São tantas as coisas que me vêm à cabeça, esta busca da estabilidade também poderia ser feita de modo a não gastar ou consumir muita energia."

0 texto continuou sendo reelaborado e no final da disciplina a professora, como veremos no relato a seguir, expressa que o conhecimento da aluna foi ampliado, mas ainda dá sinais das lacunas deste conhecimento:

"Evoluiu tua habilidade em escrever sobre assuntos de Q uímica, objetivo desta disciplina e meu objetivo particular em desenvolver capacidades que possam ser úteis na tua formação após esse "tempo de aula" que estamos tendo este ano. É claro que, como dizes, muito tens a aprender, como eu também..."

D epois de construídos argumentos mais fortes, o educar pela pesquisa implica na necessidade de comunicar os argumentos, elaborados a partir dos questionamentos, a outros sujeitos do discurso. As produções precisam ser submetidas à crítica de comunidades cada vez mais amplas. N um primeiro momento isso poderá se dar em sala de aula. As produções são lidas para os colegas e aperfeiçoadas a partir de sua crítica. Num segundo momento a comunicação pode acontecer para a escola ou serem submetidas para publicação em diferentes meios de comunicação. Esse processo pode garantir gradativamente produções de maior qualidade. A crítica e a comunicação são exigências da produção científica para a validação dos conhecimentos produzidos. U m professor, ao relatar sua análise sobre a apresentação dos alunos, corrobora com nosso entendimento de que a pesquisa é possibilidade de assunção de teorias pessoais mais fundamentadas sobre ser professor:

"Eu, assi sindo aos alunos nesseúltimo evento, vi o quanto eles aprenderam. N ão imaginei que eles tivessem aprendido tanto. $M$ as isto ficou tão internalizado todo aquele processo, que eles falavam com a mesma facilidade com que eu consegui enxergar nas 
análises. Eles falaram aquilo com uma naturalidade que eu achei espantosa. Eles desenvolveram a percepção de realidade atése colocan do como futuro professor, aquilo que eles fariam como futuro professor."

Este ciclo de questionamento, construção de novos argumentos e sua comunicação e validação crítica pode dar-se sobre qual quer tipo de conhecimento e prática. Entretanto na sua utilização na formação de professores terá como objeto preferencial o questionamento e investigação de conhecimentos e práticas relacionados à atividade docente. Assim, os objetos de estudo poderão ser as teorias didáticas pessoais, seja dos professores, seja dos alunos, implicando no questionamento das visões de ciência, de educação e de suas finalidades, de conteúdos, de metodologias e modos de avaliação, entre outros. Isto poderá ajudar os futuros professores não só a avançarem em seus conhecimentos e práticas, mas igualmente no seu entendimento epistemológico de como estes se constituem, superando visões simplistas que freqüentemente trazem (M aldaner, 1999).

Procuramos demonstrar desta forma que a formação de professores, tendo como espaço, tempo e modo de formação o educar pela pesquisa, pode concretizar-se a partir de um ciclo dialético. Iniciando-se pelo questionamento reconstrutivo, o processo direciona-se à construção de argumentos fortalecidos no diálogo crítico entre participantes, teóricos e realidade empírica, tendo como produto o processo de elaboração própria oral ou escrita. Estes argumentos são então comunicados e submetidos à crítica para seu aperfeiçoamento e fortalecimento. A aplicação deste ciclo de forma reiterada possibilita não apenas aprendizagens mais significativas aos participantes, mas pode constituir-se em nova forma de profissionalização, conforme pretendemos demonstrar a partir deste ponto.

Passamos a discutir a seguir al gumas das contribuições do educar pela pesquisa para a qualificação formal e política da formação inicial de professores.

\section{Transformações possibilitadas na formação do professor}

Pretende-se argumentar nesta parte do texto que a educação pela pesquisa na formação inicial de professores propicia uma formação mais qualificada tanto em sentido formal quanto político. 0 educar pela pesquisa propicia aos sujeitos se assumirem no discurso pedagógico e na linguagem científica, possibilitando-Ihes o desenvolvimento de competências questionadoras e argumentativas, indicadoras de uma complexificação de conhecimentos e práticas dos licenciandos. Isto por sua vez encaminha o desenvolvimento de capacidades de intervenção qualificada nas realidades educativas, tanto em sentido restrito de sala de aula como do contexto mais amplo, indicadoras de uma qualidade política da formação propiciada pelo educar pela pesquisa. Todos estes argumentos foram construídos a partir de experiências de educação pela pesquisa concretizadas junto a al unos em cursos de licenciatura, segundo se mostrará em seqüência.

A educação pela pesquisa como modo de construção de uma educação de qualidade volta-se à construção da competência dos sujeitos. D estaca-se em primeiro lugar a competência argumentativa, capacidade de construir e defender argumentos com rigor e fundamento. Um dos professores envolvidos assim se expressa neste sentido:

"(É importante)...eles começarem a estruturar argumentos. 0 importante é que eles tenham princípios como professores, que eles comecem a organizar princípios de como vão ser quando forem professores. Q ue tenham argumentos e convicções sobre isto."

0 bom professor necessita não apenas saber elaborar argumentos e defendêlos criticamente, mas também precisa ser capaz de ensinar seus alunos a produzirem argumentos e 
críticas fundamentadas. Isto implica em participação, envolvimento em diálogo, iniciativa própria, segundo aponta outro professor:

"Eu acho que os alunos participaram bastante, se posicionaram bastante. Faziam suas críticas, davam suas opi niões. D esejava-se desenvolver exatamente isso e os próprios alunos dizem isso: desenvolvimento do diálogo, participar do diálogo, se sentir capaz de falar alguma coisa."

É importante destacar também a competência de questionar, certamente elemento iniciador de qualquer processo de argumentação. $0 \mathrm{~s}$ alunos participantes das experiências apontam que o questionamento propiciado nestetipo de trabal ho é al go novo, que dificilmente vivem em seus cursos:

"O correu uma grande diferença, pois nesta disciplina o professor deu a oportunidade para 0 aluno expor suas dúvidas, seus questionamentos. U ma das diferenças foi a maneira como as aulas foram iniciadas, os comentários dos alunos fazem a aula ficar mais descontraída... U m dos pontos que mais chamaram minha atenção foi a maneira como o professor deve se colocar perante 0 aluno, sempre procurando entender a maneira como os alunos pensam para depois dar as explicações."

0 futuro professor no educar pela pesquisa não apenas aprende a questionar, mas também a respeitar os questionamentos dos outros, sendo capaz de criar um clima de questionamento e de procura de soluções em conjunto, segundo aponta um aluno participante da pesquisa:

“...estamos aqui, alunos e professores, embora diferentes intel ectualmente e como pessoas, construindo um conhecimento juntos, independentemente de ser professor e aluno. N esta disciplina não existe 0 professor que sabe. $N$ ão existe isso aqui. Professores e alunos, a gente busca solução; embora ainda não se tenha bem definido o caminho, a gente etá buscando este caminho, mas buscando junto..."

Tudo isto conduz à qualidade formal, que, entretanto, mesmo tendo no questionamento seu ponto de partida, exige ir além dele; não corresponde à crítica vazia e sem fundamentação. Ao contrário implica a busca de rigor na elaboração de argumentos, formalmente lógicos e sistemáticos, o que implica um envolvimento e dedicação intensos. Segundo um al uno o trabal ho com projetos é desafiante; ler textos, escrever e apresentar trabal hos oralmente em eventos, exigem dedicação.

A capacidade argumentativa é um dos elementos de qualidade que a educação pela pesquisa pode propiciar. Especialmente em licenciandos, geralmente com poucas vivências anteriores neste sentido, requer uma construção gradativa. Assim, mesmo tendo como meta o desenvolvimento destas capacidades em todos os participantes, é preciso respeitar os potenciais de cada al uno nos diferentes estágios de sua formação. Estas ponderações encontram fundamento nas colocações de uma das alunas:

"Eu encontro muita dificuldade em escrever; primeiro, por ter parado de estudar por 10 anos, quando retorne tive muita dificuldade com os erros de português, e por estar num curso de formação de professores estas dificuldades necessitam ser superadas, vejo uma grande melhora no meu português a cada ano, pois eu não tenho vergonha de admitir que possuo dificuldades, e tento melhorar cada vez mais, ora consultando o dicionário, ora os col egas." 
0 que se discutiu até este ponto, a qualidade formal, é de certo modo a preparação para a qualidade política. Esta, também possibilitada na educação pela pesquisa, caracterizase pela capacidade de intervenção competente. 0 futuro professor precisa desenvolver condições tanto em conhecimentos como em habilidades práticas para propor alternativas de trabaIho a partir do estudo das realidades em que se insere. Precisa desenvolver coragem para enfrentar a insegurança da mudança e ser capaz de sustentar suas propostas até mesmo em ambientes hostis. $\mathrm{N}$ isto, evidentemente, precisa saber trabalhar com os outros cooperativamente.

Em relação à qualidade política possibilitada pelo educar pela pesquisa, um professor , destacando as mudanças na sala de aula, assim se posiciona:

"A qualidade política está subjacente à proposta como um todo. Está na proposta de transformação do contexto da sala de aula, em que o aluno entende que a aula não precisa ser simplesmente o professor falando. Q ue se pode ter um crescimento de outra natureza que não necessariamente receber um conteúdo e dominar este conteúdo."

A transformação da sala de aula em modo, espaço e tempo de pesquisa pretende propiciar condições para mudanças além da sala de aula. Entretanto, num primeiro plano, cria as condições de transformação das práticas de sala de aula. Isto se aplica num primeiro movimento ao próprio professor que utiliza a pesquisa. Leva também a que o professor reconheça as limitações dos al unos em termos do papel que esperam de um professor em sala de aula. U ma professora se manifesta com clareza em relação a isto.

"Isto eu falo até mais de nós professores, E EU ME INCLUO COM LETRAS M AIÚ SCU LAS, porque dominamos a palavra e não sabemos perceber que os alunos em razão de suas aprendizagens ambientais não poderiam ter outra visão do nosso papel senão de determos a autoridade e o poder."

0 que se relata no episódio acima é que o professor que pesquisa com os alunos precisa estar atento às teorias dos alunos sobre que papel ele, professor, desempenha em sala de aula e que papel, eles, enquanto alunos, desempenham. A aula com pesquisa, mesmo considerando o conhecimento do professor sobre o tema, é um espaço de diálogo, mas no início os alunos não estão preparados a ouvir ao professor como um dos sujeitos que faz a pesquisa, mas mais como um detentor do conhecimento que irá dar as respostas verdadeiras. N este sentido, o educar pela pesquisa torna possível a complexificação da compreensão teórica e prática da atividade docente, especialmente por seu constante questionamento de teorias e práticas que fundamentam as ações em determinado momento. É especial mente importante que este questionamento se inicie com o conhecimento que os alunos e o professor já têm ao entrarem na sala de aula com pesquisa, envolvendo nisto tanto al unos como professores. Em relação a isto um dos professores destaca:

"... eu vejo também como um pressuposto importante que os alunos, como futuros professores, percebam que são incompletos, que os professores são incompletos, que existe uma incompletude neste processo. E eles vão pesqui sando junto com o professor e eles vão vendo queo professor também não sabetudo. I sto gera um profissional insatiffeito, que vai buscar cada vez mais as suas coisas. Gera um profissional preparado para nunca parar de pesquisar, de procurar. Gera um profissional preparado para a educação continuada depois da formação inicial. Há um modelo de aprendizagem implícito diferente do modelo tradicional. Eles vão pesquisando junto com o professor. H á uma transformação radical de entendimento de ensino. 0 professor é um elo 
no processo. E os alunos começam a perceber o professor como um Sujeito, incompleto e à medida que eles se constituem professores, também se dão conta de sua incompletude."

N um sentido semelhante se posiciona uma das professoras:

"Tenho aprendido muito em relação à disciplina de Prática de Pesquisa. Ela me faz refletir sempre sobre o que é ser professor e penso que tenho melhorado muito minha relação com alunos e professores em razão detas aprendizagens."

No educar pela pesquisa emergem aprendizagens privilegiadas. 0 conhecer se resignifica como oportunidade de desenvolvimento, desenvolvimento humano com autonomia e qualidade. Entretanto é importante destacar que isto se dá a partir do que os alunos e os professores são quando ingressam no processo, de suas condições teóricas e práticas de partida. É o que pode ser compreendido na fala de um aluno:

"Ficamos mais independentes do professor, consultando em livros os conteúdos trabaIhados, observando as práticas, tentando interpretá-las. Enfim, buscando por nós mesmos os recursos necessários para construir nossa aprendizagem, auxiliados pela professora sempre que precisamos, seja antes das consultas bibliográficas, seja durante esse processo. Com esse trabalho, aprendemos a tornar-nos independentes (ou quase), logo quando começarmos a trabalhar, ficando sozinhos com nossas dúvidas, acho que saberemos como melhor lidar com elas, o que nos confere mais segurança."

0 envolvimento ativo e reflexivo propiciado pela pesquisa em sala de aula de formação de professores possibilita ainda um entendimento epistemológico diferenciado. Tanto al unos como professores modificam seus entendimentos de ciência, de verdade, de como se chega a um conhecimento. N este sentido, um dos professores ressalta a questão da forma de entendimento do que constitui uma verdade:

"O ponto de viragem disso é a concepção de ciência. N o trabalho exploratório os conceitos são construídos gradativamente e parcialmente. Eles nunca são completos eacabados. Q ue verdade surge daí? É uma verdade relativa que vem da construção daquele momento. Ao se conseguir ver isso, etá sendo superada a visão positivista de ciência."

A mesma idéia aparece na fala de uma aluna: Aqui em sala de aula a gente diz que nada é pronto e acabado e eu acho que a gente pode levar isso para todas as áreas.

Assim, as novas formas do aprender a aprender implicadas no educar pela pesquisa, possibilitam aos envolvidos assumirem novos entendimentos de como se elabora o conhecimento nos indivíduos, ao superar especialmente concepções absolutistas de ciência e verdade e ao ajudar a compreender todo conhecimento como provisório e sempre inacabado.

Possibilita também construir conhecimentos mais amplos e fundamentados sobre 0 ensino, currículo, conteúdo e avaliação. N unca é demais destacar que isto sempre ocorre com possibilidades de cada participante evoluir a partir do seu conhecimento inicial. Cada aluno e professor determina onde se inicia seu processo de reconstrução.

0 educar pela pesquisa possibilita também a construção da competência profissional com autonomia. 0 envolvimento em permanentes questionamentos e críticas ajuda a formação de juízos autônomos, isentos de controle e limitações externas não profissionais. A capacidade de argumentar com rigor também caracteriza autonomia discursiva, um professor capaz de assumir-se com poder de fala no seu grupo, ainda que esta somente se desenvolva na relação com os outros. Um dos professores destaca este ponto: 
"O aluno vai se construindo com cada um dos Sujeitos que está ali. E não são ape nas os alunos que aprendem, inclusive o professor, como mediador, vai construindo seu jeito de ser, com sua história, pela ação, pela reflexão."

Ao compreendermos isto, entendemos como a educação pela pesquisa é capaz de ajudar a superar a racionalidade técnica. $\mathrm{Na}$ medida em que cada participante parte de suas próprias teorias, reconstruindo-as e utilizando-as para solucionar problemas emergentes, desenvolve-se uma nova autonomia profissional. Esta formação crítica e científica competente ajuda o professor a melhorar os processos de tomada de decisões em que se envolve, possibilitando uma mente mais aberta para a solução criativa de problemas, sempre partindo de suas próprias idéias. Isto origina uma nova forma de entender-se profissional na docência em que as soluções são criações do professor e não impostas de fora.

Retomando o que pretendemos argumentar até este ponto, sempre no sentido de defesa da tese da educação pela pesquisa como modo, tempo e espaço de formação inicial de professores, trouxemos el ementos para mostrar que esta proposta pode auxiliar a atingir a qualidade formal e política na preparação de professores. 0 envolvimento constante em pesquisa ajuda na construção de competências docentes, capazes de propiciar as condições de intervenção crítica e criativa na realidade. Com isto entende-se ser possível a emergência de professores autônomos, capazes de determinarem eles mesmos o direcionamento de seu trabalho docente.

As vivências dos experimentos práticos demonstram que um dos elementos básicos que a educação pela pesquisa possibilita é de os envolvidos serem conduzidos a realizarem os questionamentos teóricos e práticos a partir de suas próprias teorias e práticas. 0 processo propicia reconstruções gradativas tendo sempre como ponto de partida os sujeitos envolvidos, com seus conhecimentos iniciais e com suas formas de agir pessoais. $\mathrm{Na}$ medida em que as reconstruções se dão a partir destas perspectivas, os conhecimentos resultantes deste tipo de envolvimento são significativos para os participantes, estabelecendo-se uma perfeita relação entre teoria e prática.

Isto posto, surgem de imediato novos questionamentos: Em que pressupostos fundamenta-se esta abordagem de formação docente?

\section{Educar pela pesquisa e formação profissional nas licenciaturas}

Entre os que estudam e vivem os cursos de formação inicial de professores, em especial as Licenciaturas, há um consenso sobre a situação problemática destes cursos. Alguns destes problemas se arrastam desde sua origem e, neste caso, podemos nos referir em especial a separação entre conteúdos disciplinares específicos e conteúdos pedagógicos e a falta de integração entre o conhecimento trabal hado na academia sobre a realidade prática e esta realidade.

D efendemos a idéia de que a organização da formação docente, tendo como princípio formativo a educação pela pesquisa possibilita um avanço qualitativo nesta formação, podendo contribuir de forma efetiva para a dissolução destes dois aspectos. E esta pesquisa permitiu-nos perceber que esta aproximação só vai ocorrer de forma efetiva quando os alunos e professores conseguirem expressar e assumir suas próprias teorias pedagógicas. N este sentido, o educar pela pesquisa pode contribuir, justamente por ser possibilidade de pesquisa das teorias pessoais de professores e alunos, como propõe $\mathrm{G}$ aliazzi ( 2000).

Argumentamos aqui que a pesquisa quando utilizada como princípio formativo nas licenciaturas pode melhorar a qualidade da formação. A pesquisa pode trazer benefícios especialmente num exercício de aproximação teoria e prática ao fazer uma aproximação dialética 
entre disciplinas de conteúdos específicos e disciplinas pedagógicas. Esta aproximação necessariamente precisa dar-se a partir do sujeito que pensa e age.

0 desenvolvimento de projetos integrados por meio do educar pela pesquisa ajuda a aproximar o mundo da formação acadêmica da realidade da sala de aula, tornando a prática mais significativa. Ajuda aos formandos a se impregnarem na teoria dentro da prática ao possibilitar ir à realidade e examiná-la a partir de bases teóricas. É, portanto, uma forma de aproximação entre teoria e prática (M oraes e G aliazzi, 2000).

Por ser essencialmente um processo de questionamento e argumentação, o educar pela pesquisa constitui-se num exercício permanente de reflexão sobre a prática. É importante que este questionamento se inicie com a reflexão sobre as próprias teorias e práticas dos licenciandos, ajudando no conhecimento das próprias idéias e modelos pedagógicos, propiciando avançar em relação a eles. A partir disto a pesquisa pode direcionar-se a refletir sobre conhecimentos e práticas das realidades em que os futuros professores atuarão, criando alternativas de intervenção nestes contextos (H arres, 2000; Porlán, 1998).

D essa forma defendemos que a educação pela pesquisa possibilita uma teorização da prática, de modo a superar a dicotomia teoria/prática que tem caracterizado a relação entre estes dois domínios. É uma forma possível de dial etizar teoria e prática, possibilitando a emergência de uma práxis como ação informada. D efendemos a idéia de que isso precisa ser desencadeado a partir da assunção dos participantes.

Projetos dessa natureza constituem-se em oportunidades de cooperação e crescimento mútuo entre a academia e a escola. Ao longo do tempo poderão auxiliar na solução de problemas das escolas, influindo sobre o currículo e possibilitando iniciativas de educação continuada dos professores. É essencial, entretanto, que essas iniciativas sejam cooperativas, compreendendo-se todos os envolvidos como sujeitos pensantes e reflexivos. A academia constitui-se em mais um parceiro no processo.

$\mathrm{N}$ isso entendese também a profissionalização do docente por meio da pesquisa. A construção gradativa da competência profissional será sempre compreendida como um processo permanentemente inacabado. 0 futuro professor terá consciência de que sua formação nunca estará concluída, mas que precisa efetivar-se pelo permanente questionamento de seus conhecimentos e de sua prática.

Certamente o caminho proposto não é isento de resistências e dificuldades. As resistências e incompreensão do processo do educar pela pesquisa se manifestam em todas as instâncias de sua utilização e um olhar atento a essas manifestações pode sinalizar para as visões dos envolvidos que limitam as possibilidades de construção de entendimentos pedagógicos mais complexos. O s limites se apresentam no conhecimento profissional compartimentado dos professores, com visões pedagógicas ainda presas a um entendimento tradicional de currículo, ensino, aprendizagem e avaliação. Esse ensino ainda muito centrado nos conteúdos disciplinares, sustentado por um entendimento de aprendizagem como assimilação de conteúdos transmitidos e, geralmente, com uma avaliação classificatória do produto. As resistências aparecem ainda mais fortes nos alunos, pouco acostumados a questionar e refletir sobre o que é ser professor.

Se aparecem resistências que apontam limites, as possibilidades as superam. 0 s alunos aprendem uma proposta com qualidade política, centrada na aprendizagem do aluno, com qualidade formal, e se constituem professores em um diálogo fundamentado. Além disto, começam a conceber-se professores, realidade pouco presente nos cursos de Licenciatura, e mais que isto, passam a assumir a sua formação como um processo permanente. 0 utro conjunto de aprendizagens se refere à competência profissional, que pode ser construída através 
do questionamento do conhecimento inicial de alunos e do professor. Essa competência se enriquece com a construção de argumentos fortalecidos no diálogo com a teoria e com a prática. 0 s argumentos construídos podem ser validados por meio da argumentação em comunidades de diálogo mais amplas (G aliazzi, 2000).

0 educar pela pesquisa exige que também se construa simultaneamente uma compreensão sobre as teorias didáticas pessoais do professor em processos semelhantes aos aqui apresentados, em coletivos de pesquisa com seus pares. Como afirma Tancredi (1998) para mudar a formação de professores é preciso tornar mais complexos os conhecimentos profissionais tanto dos professores das disciplinas específicas como dos que atuam de dentro da área pedagógica.

A formação de professores tem sido historicamente criticada pela incapacidade de estabelecer uma relação complementar entre teoria e prática. D efendemos a tese de que a educação pela pesquisa é um modo, tempo e espaço de formação que possibilita superar esta limitação, porque o formador e o licenciando, pelo educar pela pesquisa, podem assumir suas próprias teorias pedagógicas.

0 educar pela pesquisa permite ampliar as possibilidades de atingir tanto a qualidade formal como política na formação de professores. A primeira é representada pela construção de conhecimentos mais significativos, pela aquisição de competências profissionais, pelo aprender a aprender que tal abordagem possibilita. Já a qualidade política que emerge do educar pela pesquisa aparece em forma de uma autonomia crescente, da capacidade crítica e da competência para transformação das realidades em que o futuro professor se envolve.

Essas possibilidades concretizam-se a partir do uso de um conjunto de princípios que o educar pela pesquisa: o questionamento reconstrutivo, o diálogo crítico, não só com colegas e professores, mas, sobretudo com interlocutores teóricos, práticos e empíricos, o exercício do pensar e do escrever, com vista ao argumentar rigoroso e fundamentado.

Entendemos que esse processo pode ser organizado a partir de círculos reiterativos de pesquisa constituídos de três movimentos principais: questionamento, construção e validação de argumentos. No primeiro, questiona-se verdades teóricas ou práticas existentes; a partir disso constroem-se novos argumentos, capazes de se transformarem em novas verdades; os resultados desse processo, mesmo que sempre parciais e inacabados, são comunicados para validação crítica em comunidades de discurso diversificadas.

Em síntese, na tese da formação docente pela pesquisa estabelecem-se relações muito produtivas entre investigação e formação de professores. Supera-se a racionalidade técnica transformando todos os envolvidos em sujeitos participantes do processo de pesquisar. Os licenciandos passam de objetos a sujeitos do seu processo de formação, fundamentando suas visões pedagógicas. Aproxima-se a teoria da prática, o conhecimento acadêmico do conhecimento prático; integram-se conhecimentos compartimentados nas diferentes disciplinas curriculares. D essa forma, a pesquisa constitui-se em modo, tempo e espaço de construir qualidade na formação docente.

\section{Referências bibliográficas}

DEM O, P. Educar pela pesquisa. Campinas: Autores Associados, 1997 .

. Pesquisa e construção de conhecimento. Rio de Janeiro: Tempo Brasileiro, 1997b.

GALIAZZZI, M .C. Educar pela pesquisa: espaço de transformação e avanço na formação inicial de professores de Ciências. Porto Alegre, 2000. Tese (D outorado em Educação) Faculdade de Educação, Pontifícia Universidade C atólica do Rio Grande do Sul, 2000. 
GU STAVO, B. Educação pelo argumento. Rio de Janeiro: Rocco, 2000.

H ARRES, J.B.S. A reflexão sobre os problemas práticos profissionais: análise de um caso na formação de professores na área de Ciências. Caderno Pedagógico, n. 3, p. 43-64, jul. 2000. M ALD AN ER, O . A. A pesquisa como perspectiva na formação continuada do professor de Q uímica. Química Nova, v. 22, n. 2, p. 289-292, 1999.

M ORAES, R. A pesquisa na educação dos professores de química. Conferência apresentada no XVII EDEQ. Ijuí, 24-27 out. de 1997.

PORLÁN, R. La formación inicial de maestros en Didáctica de las Ciencias. Investigación en la Escuela, n. 35, p. 33-42, 1998.

PORLÁN, R., RIVERO, A. El conocimiento de los profesores. Sevilla: Díada, 1998.

TAN CREDI, R. M . S. A prática de ensino e o estágio supervisionado na formação e na atuação dos professores: enfrentando desafios ou desafiando lógica vigente. In: EN CON TRO N ACIONAL DE DIDÁTICA E PRÁTICA DE EN SIN 0, 9. Águas de Lindóia, 4-8 maio 1998. Anais... Águas de Lindóia, 1998. p. 358-375.

\section{Artigo recebido em março de 2002 e selecionado para publicação em novembro de 2002.}

